\title{
Materiales metálicos y reciclaje
}

\section{INTRODUCCIÓN}

El presente artículo analiza algunos aspectos energéticos, tecnológicos y ambientales del reciclaje de materiales metálicos, en especial de los metales no ferrosos básicos, como el aluminio, el cobre, el plomo y el zinc.

Se comparan las materias primas de origen primario (minerales) y secundario (chatarra), poniendo énfasis en la calidad y clasificación de las materias primas secundarias para una comercialización adecuada. De igual manera, se revisan las tecnologías actuales disponibles para el reciclaje de metales no ferrosos.

\section{MATERIAS PRIMAS DE ORIGEN PRIMARIO Y SECUNDARIO}

En relación con las materias primas metálicas, cabe diferenciar entre las materias primas de origen primario: los minerales, concentrados y metales refinados que se comercializan en el mercado mundial y provienen de la extracción directa de los yacimientos, y las de origen secundario: chatarra de procesamiento y fabricación (chatarra nueva o interna), los desechos de los artículos de consumo, maquinarias, etcétera, que han cumplido su tiempo de vida (chatarra vieja o residual), y los residuos de producción que pueden contener valor metáli- 
cos interesantes como polvos de fundición, escorias, etcétera. La figura 1 muestra esquemáticamente los flujos de producción y consumo de materiales metálicos.

En la actualidad, cuando el aspecto ambiental y el desarrollo sostenible tienen gran importancia, es necesario recordar que los metales han sido reciclados desde tiempos remotos por varias razones obvias, principalmente por su valor (en el caso de metales preciosos, su valor es tan alto que los desechos rara vez son desperdiciados). Por otro lado, el costo de los metales que se obtienen a partir de la chatarra es menor que el de los que se obtienen a partir de las materias primas originales, y en épocas de escasez o gran demanda (periodos de crisis, guerras, etcétera) se reciclan grandes cantidades de chatarra como materia prima.

Fig. 1

Producción y consumo de materiales metálicos

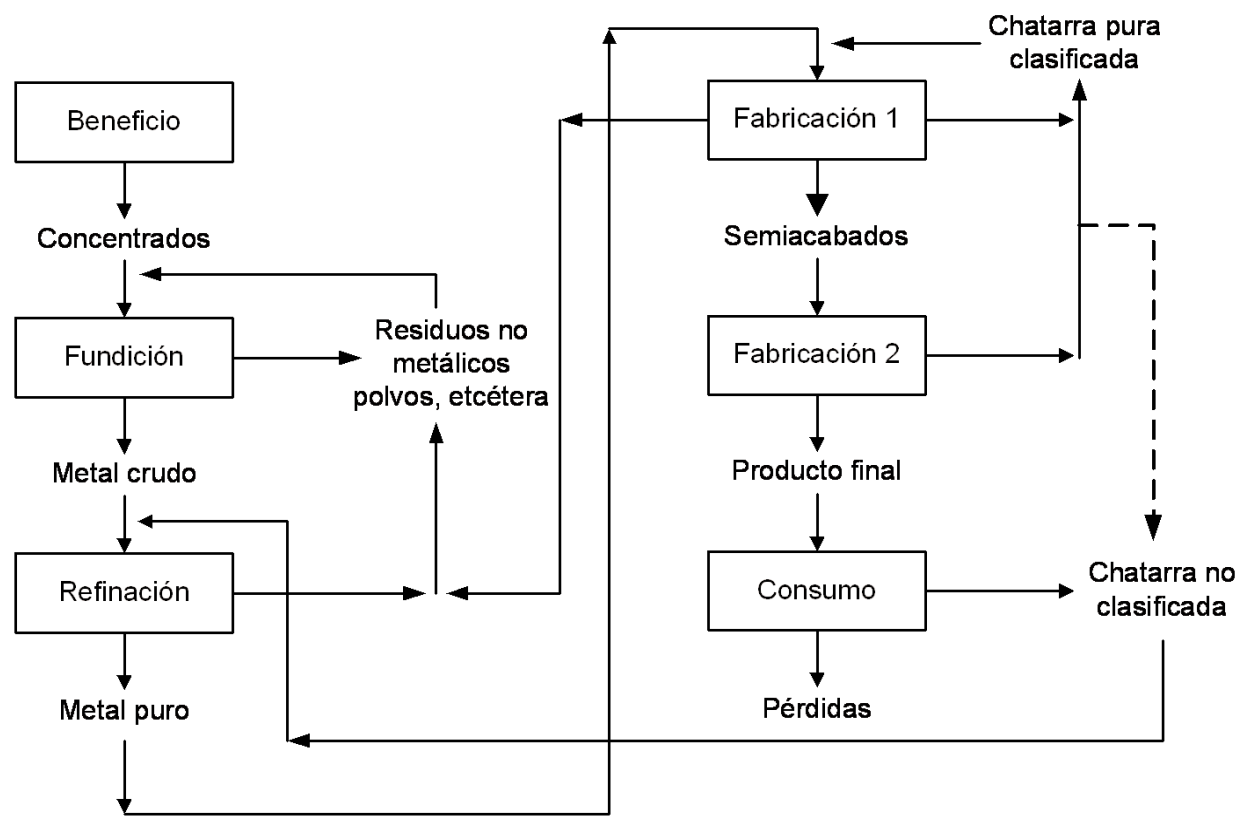

Fuente: Universidad Tecnológica de Aquisgrán, 1990. 
Los metales, a diferencia de otros materiales como los polímeros termoplásticos, se pueden reciclar casi indefinidamente, recobrando sus propiedades iniciales, aunque no siempre con facilidad. Sin embargo, la posibilidad de una recuperación económica depende de cómo se empleó el metal inicialmente y de su reactividad. Los metales no son consumidos sino usados para un propósito específico, por un periodo de tiempo limitado. El cobre, el plomo y el acero pueden reciclarse muchas veces, a menudo con una pequeña disminución de la calidad o, en el caso de algunas aleaciones, con menor calidad después de un reciclaje primario o secundario (tabla 1).

Tabla 1

Calidad de los metales reciclados

\begin{tabular}{ll}
\hline Metal & Posibilidad de refinación \\
\hline Cobre, plomo, zinc & completa \\
Aluminio, hierro y acero & limitada \\
Ferroaleaciones & solo en casos especiales \\
\hline
\end{tabular}

Fuente: Universidad Tecnológica de Aquisgrán, 1990.

En el mercado mundial la demanda de chatarra está en relación con la estructura de la industria y la disponibilidad de tecnologías de producción para crear valor agregado a partir de las materias primas secundarias. Este mercado complejo depende de las decisiones de varios actores independientes, como los comerciantes de chatarra, intermediarios, desmanteladores y fundidores. Los criterios de reciclaje de metales en función de la oferta de chatarra se resumen en la tabla 2.

Tabla 2

Criterios para el reciclaje de metales

\begin{tabular}{lll}
\hline Oferta de chatarra & alta & baja \\
\hline Precio del metal & alta & bajo \\
Utilización & alta & baja \\
Facilidad de obtención & fácil & difícil \\
Pureza (contenido metálico) & alto & bajo \\
Duración & corta & larga \\
\hline
\end{tabular}

Fuente: Universidad Tecnológica de Aquisgrán, 1990. 
La energía requerida para la producción de metales a partir de chatarra es considerablemente menor a la que se necesita para obtener los metales a partir de las fuentes originales (minerales y concentrados). La razón principal es que la fusión del metal requiere menos energía que la reducción a partir de los óxidos o sulfuros presentes en las materias primas. Con frecuencia se escucha el argumento de la industria del aluminio de que se deben reciclar las latas de bebidas usadas porque esto ahorraría el 95\% de la energía utilizada para producir el aluminio primario, lo cual es cierto pero relativo, pues la producción de aluminio primario por electrólisis en baño fundido consume cerca de $14 \mathrm{kWh}$ de energía por kilogramo de metal refinado, mientras que para otros metales, como el hierro, cobre, plomo y zinc el consumo específico de energía varía entre 6 y $8 \mathrm{kWh}$ de energía por kilogramo, para la producción primaria, con un promedio de ahorro energético de $70 \%$ para el acero y $80 \%$ a $85 \%$ para el cobre. La figura 2 muestra las cifras parciales y totales de consumo energético para distintos metales.

También hay que tener en consideración el impacto ambiental que significa la producción de metal primario, por la generación de residuos (lodos, polvos, escorias, etcétera); para el caso del aluminio se generan 2,7 toneladas de residuos (principalmente los "lodos rojos" del proceso Bayer de disolución cáustica de la bauxita) por cada tonelada de metal refinado. Para las materias primas secundarias la incidencia es mucho menor.

Fig. 2

Consumo específico de energía en la producción de metales.

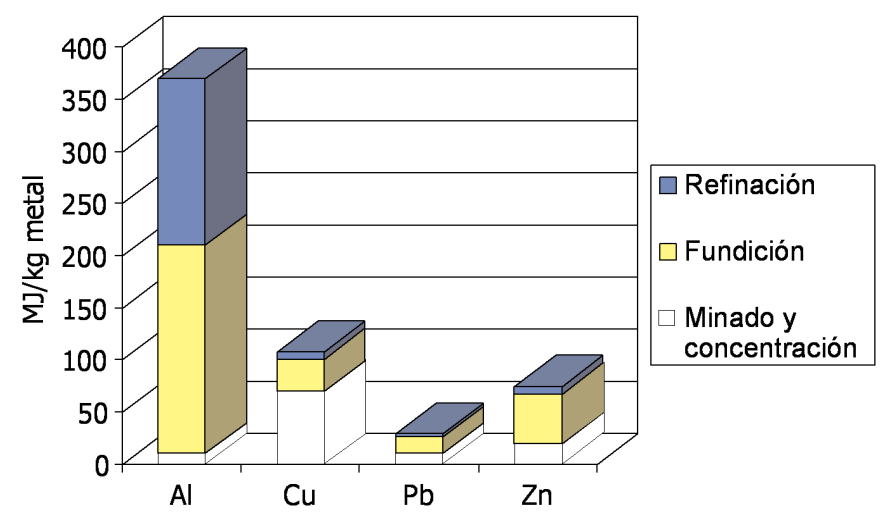

Fuente: Universidad Tecnológica de Aquisgrán, 1990. 
Las tasas de reciclaje de metales en los países industrializados varían entre $30 \%$ y $55 \%$ de la demanda total anual de metal y están en incremento (en algunos casos como el acero y el plomo se alcanzan tasas mayores, tabla 3). Cuanto más grandes son las reservas de metal en la "tecnósfera", es mayor el potencial para reciclaje. La razón por la que las tasas de reciclaje no son aún mayores es que el crecimiento económico y la duración de los productos metálicos son factores limitantes. Por ejemplo, el ciclo de vida de la mayoría de los productos de cobre es de 30 a 50 años; si se toma como promedio los 40 años, y se compara la demanda anual de cobre de esa época, que era de 6,2 millones de toneladas, con los 18,7 millones de toneladas del año 2000, se concluye que aun si el total de la producción de cobre como chatarra de 1960 estuviese disponible actualmente, este solo alcanzaría para un tercio de la demanda actual.

Tabla 3

Tasas de reciclaje de metal en Europa (\%)

\begin{tabular}{lcc}
\hline Metal & $\mathbf{1 9 8 0}$ & $\mathbf{2 0 0 0}$ \\
\hline Aluminio & 28 & $60-70$ \\
Cobre & 37 & $50-60$ \\
Plomo & 52 & $55-65$ \\
Zinc & 33 & $65-75$ \\
\hline
\end{tabular}

Fuente: Universidad Tecnológica de Aquisgrán, 1990.

A continuación se muestra el consumo aparente y la recuperación de chatarra nueva y vieja de distintos metales básicos en Estados Unidos, durante el año 1996 (tabla 4).

Tabla 4

Consumo aparente y recuperación de chatarra nueva y vieja de varios metales en Estados Unidos (1996)

\begin{tabular}{lcccl}
\hline Metal & $\begin{array}{c}\text { Cons. aparente } \\
\text { (miles de TM) }\end{array}$ & $\begin{array}{c}\text { Chatarra nueva } \\
\text { recuperada }\end{array}$ & $\begin{array}{c}\text { Chatarra vieja } \\
\text { recuperada }\end{array}$ & Comentarios \\
\hline Acero & 112.000 & 38.000 & 32.000 & \\
Aluminio & 6.300 & 1.700 & 1.400 & $60 \%$ de chatarra vieja de envases \\
Cobre & 2.700 & 880 & 400 & \\
Plomo & 1.550 & - & 1.000 & $88 \%$ de baterías de autos \\
Zinc & 1.470 & 240 & 115 & $55 \%$ del consumo \\
Estaño & 48.4 & 4,4 & 7,6 & $30 \%$ del consumo aparente a estañado \\
\hline
\end{tabular}

Fuente: Wernick, Themelis, 1998. 
El reciclaje de los metales es, además, una actividad lucrativa. En el 2003 en Estados Unidos operaban unos 12 mil desmanteladores de autos usados y 3.000 procesadores de chatarra, que produjeron cerca de 13,9 millones de toneladas de hierro y acero para reciclaje, suficiente para producir 14 millones de autos nuevos. De hecho, la tasa de reciclaje de chatarra de automóviles fue de 102,9\% en ese año; es decir, se recicló más acero de autos que el necesario para la producción de nuevos vehículos. Otras cifras que recalcan la importancia económica y ecológica del reciclaje son los 30 mil puestos de trabajo creados desde 1970. En 1985, dos millones de recolectores de latas de aluminio han generado ganancias por US\$200 millones. La sociedad norteamericana descarta unos 35 mil millones de latas de aluminio anualmente. El reciclaje de todo este material ahorraría en energía el equivalente a 150 veces el petróleo derramado por el Exxon Valdez en 1989. De hecho, se descarta la suficiente cantidad de aluminio como para reconstruir totalmente la flota aérea comercial cada tres meses. La duración y tasas de reciclaje de diferentes productos de aluminio se muestran en la tabla 5 .

\section{Tabla 5}

Duración promedio y tasas de reciclaje de productos de aluminio

\begin{tabular}{lcc}
\hline Usos & Duración promedio en años & \% de reciclaje \\
\hline Envases & 1 & 25 \\
Transporte & $10-30$ & 50 \\
Doméstico y oficina & $1-12$ & 25 \\
Electrotécnica & 12 & $>30$ \\
Industria mecánica & 16 & $>25$ \\
Construcción & $30-50$ & 70 \\
\hline
\end{tabular}

Fuente: Universidad Tecnológica de Aquisgrán, 1990.

\section{TECNOLOGÍAS DE PRODUCCIÓN DE METAL SECUNDARIO}

\section{1 Hierro y acero}

El hierro y su producto refinado, el acero, constituyen los metales más usados (la producción mundial ya superó los mil millones de toneladas en el 2004), y el reciclaje de la chatarra ferrosa constituye una impor- 
tante actividad a escala mundial. Debido a que es económicamente ventajoso reciclar el hierro y el acero por fusión y colada, en forma de semiacabados usados en la manufactura de nuevos productos de acero, se ha desarrollado una industria significativa para recolectar la chatarra vieja (productos de acero usados y obsoletos) y chatarra nueva (la chatarra ferrosa generada en las acerías y plantas de producción). La tasa promedio de reciclaje de la industria norteamericana del acero en el 2003 fue de 71\%, según el Instituto Americano del Hierro y el Acero (AISI, por sus siglas en inglés), variando entre $60 \%$ para latas de acero, $90 \%$ para artefactos, $96 \%$ para material estructural y $103 \%$ para automóviles.

La gran cantidad de chatarra ferrosa disponible para el reciclaje comprende chatarra interna, inmediata y obsoleta. La chatarra inmediata o industrial se genera en las plantas que fabrican productos de acero. Sus características químicas y físicas son conocidas y usualmente se transporta rápidamente a las acerías para ser refundida, ahorrando espacio de almacenamiento y costos de control de inventarios. La chatarra interna o de planta se genera dentro de la acería durante la producción (retazos, recortes) y se recicla rápidamente en el horno, porque su composición es conocida; su disponibilidad, sin embargo, ha ido disminuyendo a medida que la industria fue adoptando métodos más eficientes de colada.

La chatarra vieja y obsoleta también está disponible para el reciclaje. La fuente más importante son los automóviles en desuso, seguidos de las demoliciones de estructuras de acero, de vagones y rieles de tren gastados, y de artefactos y maquinaria. Debido a la gran variedad de características químicas y físicas, la chatarra obsoleta requiere más preparación, como la clasificación, desestañado y descincificado.

Las acerías funden la chatarra en convertidores básicos de oxígeno (BOF), hornos de arco eléctrico (EAF) y, en menor proporción, en altos hornos (BF). La proporción de chatarra en la carga del BOF está limitada a menos de $30 \%$, mientras que en el EAF puede alcanzar 100\%; sin embargo, la presencia de elementos residuales como zinc, cobre, cromo y molibdeno pueden causar defectos en el producto final, por lo que a veces es necesaria la dilución con chatarra limpia, hierro de reducción directa (DRI) o arrabio. En Estados Unidos aproximada- 
mente el $49 \%$ de la producción de acero proviene de BOF, que usan solo $26 \%$ de chatarra; el $51 \%$ restante proviene de $\mathrm{EAF}$, que usan $72 \%$ de chatarra. El resto de la chatarra se funde en altos hornos y otro tipo de hornos. (Las siglas que están entre paréntesis son del inglés).

Muchos metales usados comúnmente para aleación en los aceros, para mejorar sus propiedades (resistencia, maquinabilidad) continúan el mismo proceso de reciclaje, como el molibdeno y el vanadio, que se recuperan mayormente de la chatarra ferrosa. El caso del manganeso, por ejemplo, es más drástico, pues como metal individual se recupera una cantidad despreciable, mientras que la cantidad más considerable se obtiene del reciclaje de chatarra ferrosa y escorias de hierro y acero.

Como ejemplo representativo de la recuperación de chatarra de acero y otros metales se describe a continuación el proceso aplicado con los automóviles usados. La figura 3 muestra una típica instalación de procesamiento de chatarra de automóviles. En la primera etapa se

Fig. 3

Planta de procesamiento de chatarra de automóviles.

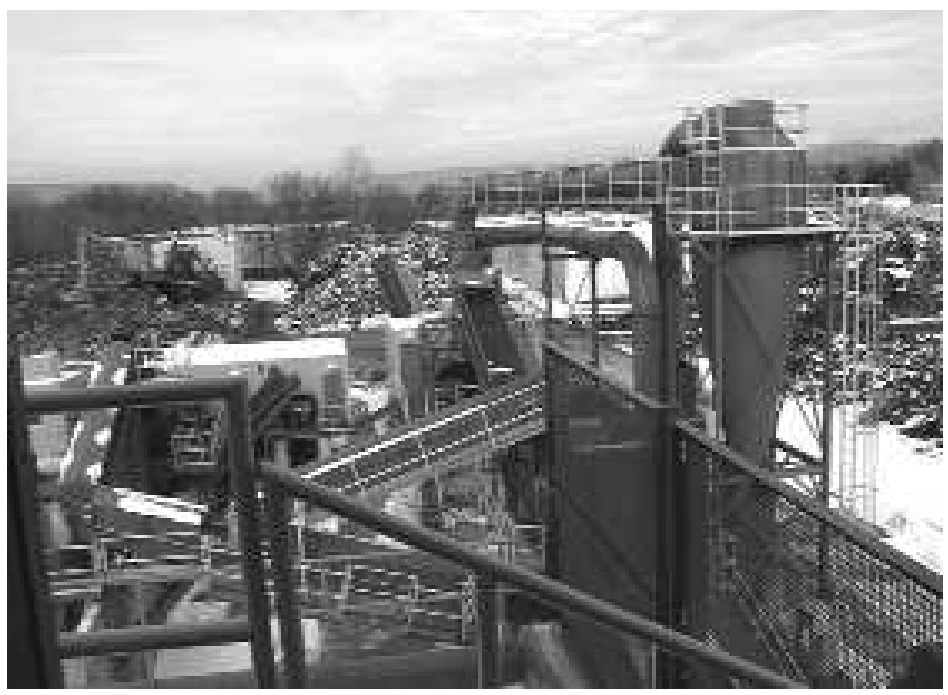

Fuente: Japan Automobile Manufaturers Association (JAMA). 
separan los componentes usados, cuyo valor como piezas de repuesto sobrepasa largamente el de contenido metálico; después de que se han retirado las partes utilizables, los automóviles son triturados en un equipo conocido como shredder, produciendo una fracción metálica ferrosa y otra no ferrosa, así como un residuo no metálico (ASR, automotive shredder residue), que contiene plásticos, vidrio, caucho, alfombras, etcétera.

La separación del hierro y el acero aprovecha también las propiedades magnéticas de estos metales. Los avances científicos para el tratamiento de materiales han conducido a la introducción de magnetos permanentes de tierras raras con elevada fuerza de campo (los magnetos de neodimio-boro-hierro generan campos de más de 35 millones de gauss-oersted) que no requieren electricidad para operar y que producen campos magnéticos suficientemente potentes que permiten recuperar incluso los aceros inoxidables débilmente magnéticos.

Para recuperar las fracciones metálicas no ferrosas de corrientes mixtas se emplean métodos basados en las diferencias de propiedades físicas como la densidad. Así, a través de corrientes de aire, de medios densos (HMS) y de ciclones se logran separar las fracciones livianas de las más pesadas. De este modo, se obtiene una alta recuperación de la fracción metálica (90 a 95\%), pero siempre quedan los residuos mixtos de poco valor, como el ASR. Estos eran depositados como basura residual, pero en la medida en que la legislación ambiental establece límites más estrictos para estos desechos, se han desarrollado nuevos procesos para su tratamiento. La figura 4 muestra el esquema de un proceso de destilación seca y gasificación desarrollado en Japón para tratar térmicamente el ASR.

El acero inoxidable es otro ejemplo de aleación de hierro con otros metales. Estas aleaciones contienen, además de hierro, cromo y níquel, pequeñas cantidades de otros metales. Por su excelente resistencia a la corrosión tienen un ciclo de vida económico más largo. Esta longevidad disminuye la necesidad inmediata de reemplazo por metal nuevo o reciclado. Como en el caso de otras aleaciones especiales, ha proliferado una gran variedad de aceros inoxidables; sin embargo, actualmente solo dos tipos representan el $65 \%$ de la producción mundial total: AISI $304(18 \mathrm{Cr}-8 \mathrm{Ni})$ y AISI $316(16 \mathrm{Cr}-10 \mathrm{Ni})$. Este número reducido de aleaciones aumenta la posibilidad de desarrollar un sistema de reciclaje cerrado. 


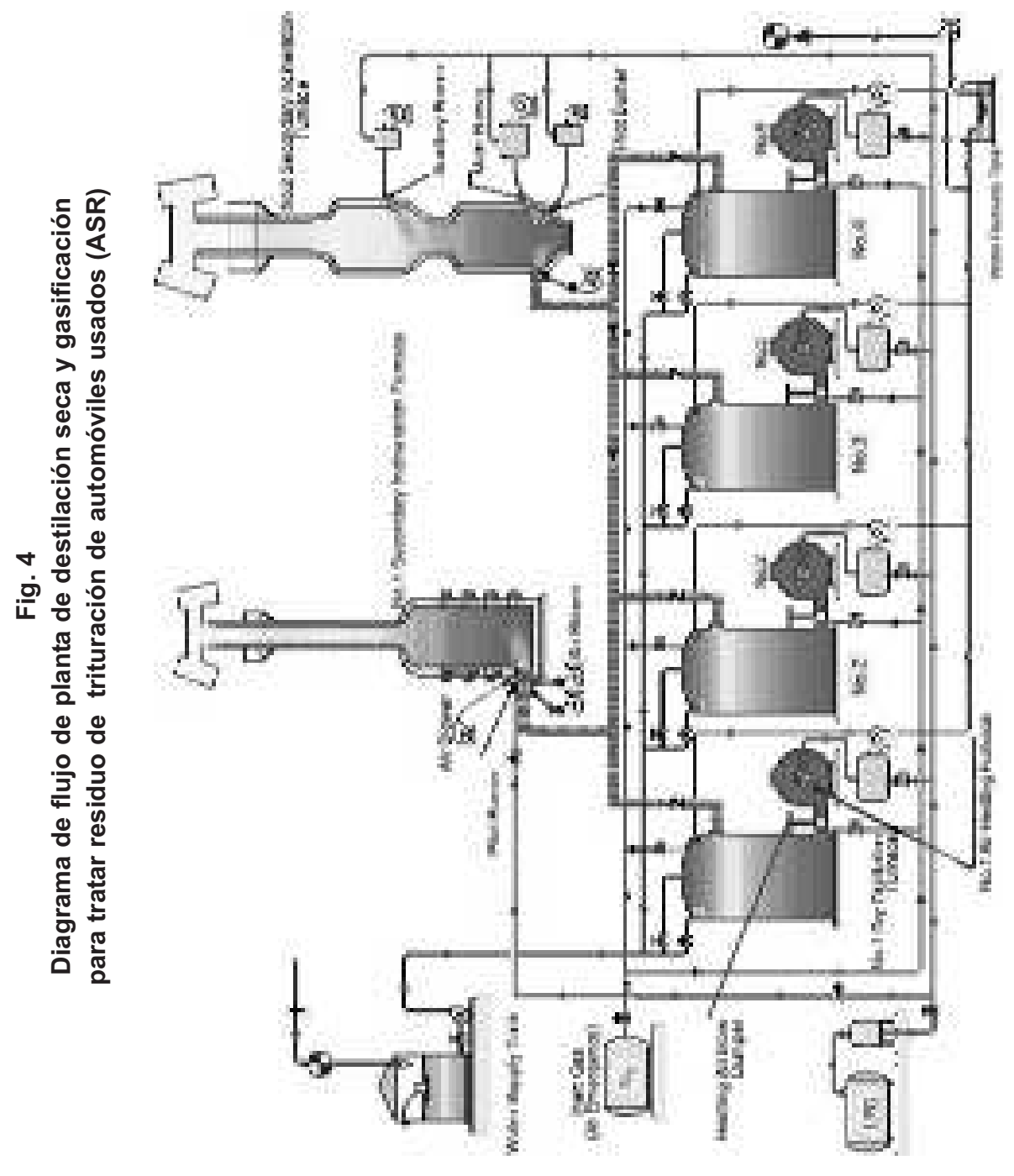

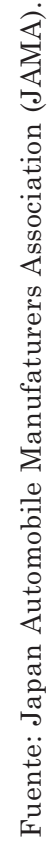




\subsection{Aluminio}

Después del acero, el segundo metal en importancia es el aluminio, aunque el valor de la chatarra reciclada es mayor que la del acero. La producción mundial de aluminio primario es de 22 millones de toneladas por año, y, desde la Segunda Guerra Mundial, ha ido en crecimiento, logrando desplazar al cobre al tercer lugar.

En el caso del aluminio, la diferencia entre la chatarra nueva y la chatarra vieja es más patente, debido a la alta reactividad del metal y la imposibilidad práctica de una refinación a partir de fuentes contaminadas. La chatarra de aluminio clasificada se procesa en un horno de reverberación, donde el calor es irradiado desde el techo y las paredes hacia el baño metálico. Las capacidades de fusión alcanzan las 5 a $6 \mathrm{t} / \mathrm{h}$ de chatarra y la escoria producida ("costra") contiene hasta $20 \%$ de aluminio. En Alemania es común el método de fusión en horno rotatorio con adición de sal y refinación adicional e inyección de gases inertes (figuras 5 y 6). El metal producido es aleado y colado en lingotes o transportado en estado líquido en contenedores especiales a las fundiciones y posteriormente a las plantas de fabricación de motores. La escoria salina producida es tratada, para regenerar la sal para el proceso de fusión.

Fig. 5

Esquema simplificado de producción de aluminio secundario a partir de chatarra

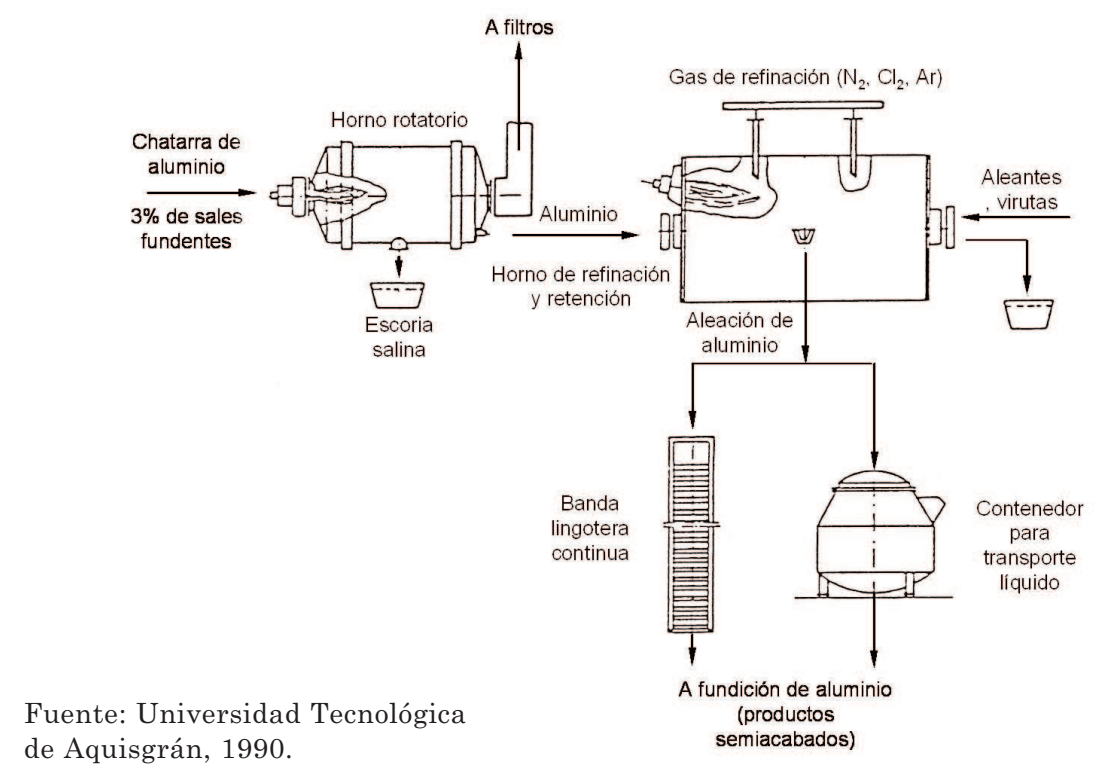


Fig. 6

Procesamiento de chatarra de aluminio en horno rotatorio y transporte de aluminio líquido
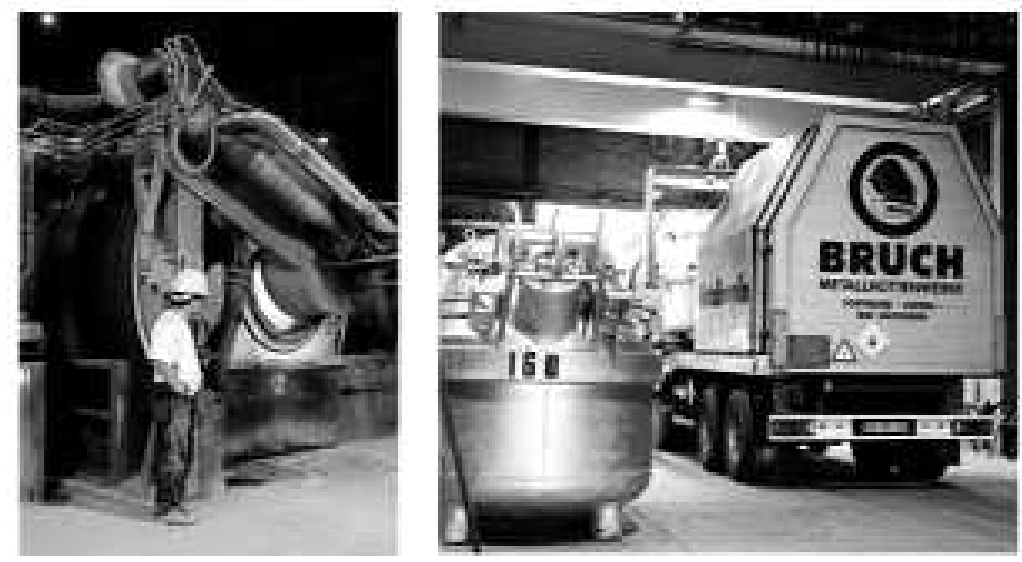

Fuente: Bruch Metallwerke.

\subsection{Cobre}

En el caso del cobre, el metal reciclado puro puede ser refundido y combinado con cobre primario. El cobre aleado o mezclado físicamente con otros metales es tratado en fundiciones primarias o secundarias y colado en ánodos junto con el metal virgen previo a la electrorrefinación. La chatarra clasificada de aleaciones de cobre puede usarse como materia prima en fundiciones de latón y bronce.

Las fundiciones secundarias de cobre procesan chatarra de bajo grado con coque, en un horno de cuba (proceso Knudsen, 1915), para producir un cobre impuro ("negro") que contiene plomo, zinc, estaño y otras impurezas (figura 7). Los elementos volátiles, como los óxidos de plomo y de zinc, se remueven por oxidación parcial para producir cobre blíster.

El reactor Kaldo, de la corporación Boliden, en Suecia, usa otro proceso para fundir chatarra de cobre de bajo grado. En este proceso, la chatarra de metal, que contiene en promedio $40 \%$ de cobre, $10 \%$ de zinc y $15 \%$ de hierro, se deposita en un horno rotatorio inclinado; se añade coque según lo que se requiera y se inyecta aire enriquecido con oxígeno a través de una lanza. El calor de oxidación del hierro, zinc y plomo volatiliza los óxidos metálicos y produce cobre impuro y una escoria rica en hierro con menos de $0,5 \%$ de cobre y zinc. 
Fig. 7

Procesamiento de chatarra y residuos de cobre.

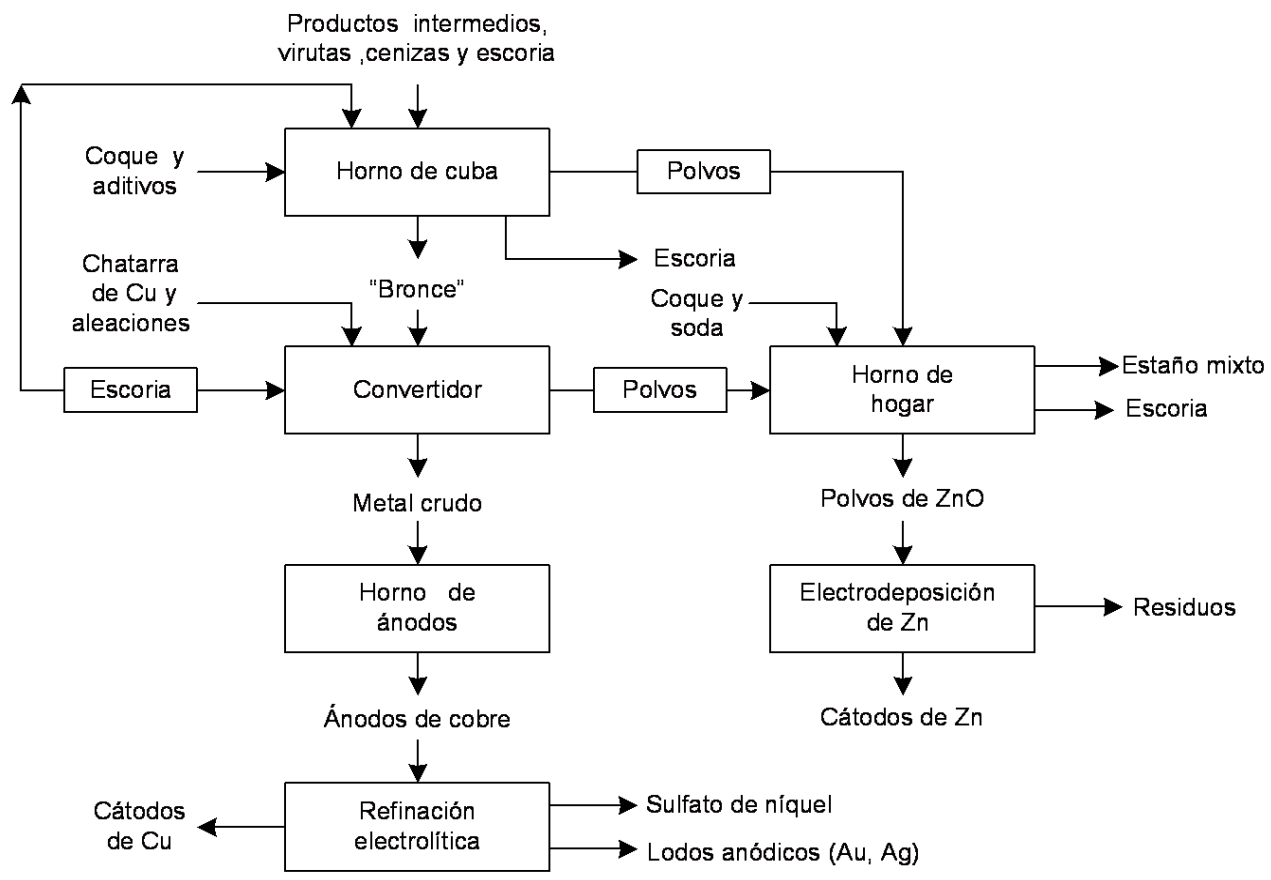

Fuente: Universidad Tecnológica de Aquisgrán, 1990.

\subsection{Plomo}

La mayor fuente de reciclaje de chatarra de plomo la constituyen las baterías de automóviles. La típica batería (en realidad el acumulador) de plomo consiste en una carcasa de polipropileno, con bornes y electrodos de plomo (mallas), espaciadores de plástico entre los electrodos, pasta de óxido de plomo $\left(\mathrm{PbO}_{2}\right.$ y $\left.\mathrm{PbSO}_{4}\right)$ y ácido sulfúrico. La tabla 6 muestra la composición típica en peso de una batería (acumulador) de automóvil. 
Tabla 6

Composición típica de una batería de automóvil (12 V, 44 Ah)

\begin{tabular}{lcr}
\hline Componente & $\mathbf{k g}$ & \multicolumn{1}{c}{$\%$} \\
\hline Ácido sulfúrico & 3.85 & 28,50 \\
Caja & 0,67 & 5,00 \\
Separadores & 0,34 & 2,50 \\
Plomo & 8.64 & 64,00 \\
• rejilla metálica & 3.00 & 22,20 \\
• polos & 0.80 & 5,90 \\
• pasta & 4.84 & 35,90 \\
Total & 13.50 & 100,00 \\
\hline
\end{tabular}

Fuente: Universidad Tecnológica de Aquisgrán, 1990.

En una planta de reciclaje las baterías son trituradas o cortadas y separadas en tres corrientes: materiales de plomo $\left(60 \% \mathrm{~Pb}, 15 \% \mathrm{PbO}_{2}\right.$ y $12 \% \mathrm{PbSO}_{4}$ ), chatarra de polipropileno y ácido sulfúrico. Los materiales que contienen plomo son fundidos para producir un bullion de plomo y una escoria de silicato fundido que contiene todos los óxidos de plomo. Este subproducto es fundido y reducido con material carbonáceo y fundentes en un horno de cuba. La escoria de bajo plomo producida en este horno es inerte en el ambiente y puede ser depositada en rellenos industriales.

Una variante muy eficiente del procesamiento de baterías usadas es el proceso de la refinería de plomo-plata de la empresa Berzelius, en Braubach, Alemania (figura 8). Las baterías usadas son trituradas $\mathrm{y}$, por medio de un tamiz, separadas en material grueso (rejilla, polos, PVC, PP, plásticos reforzados con fibra de vidrio, etcétera) y material fino (resto de rejillas, pasta). Del material grueso se puede obtener por separación hidráulica las fracciones livianas (PP, PVC) y pesadas (principalmente el plomo), mientras que el material fino es tratado en un agitador con carbonato de sodio, convirtiendo todo el plomo restante en carbonato. El plomo y el carbonato de plomo se funden en un horno rotatorio corto con adición de carbón o coque y se refinan. El sulfato de sodio formado en el agitador puede precipitarse por cristalización y venderse como producto seco. 
Fig. 8

Esquema simplificado del procesamiento de baterías usadas de autos

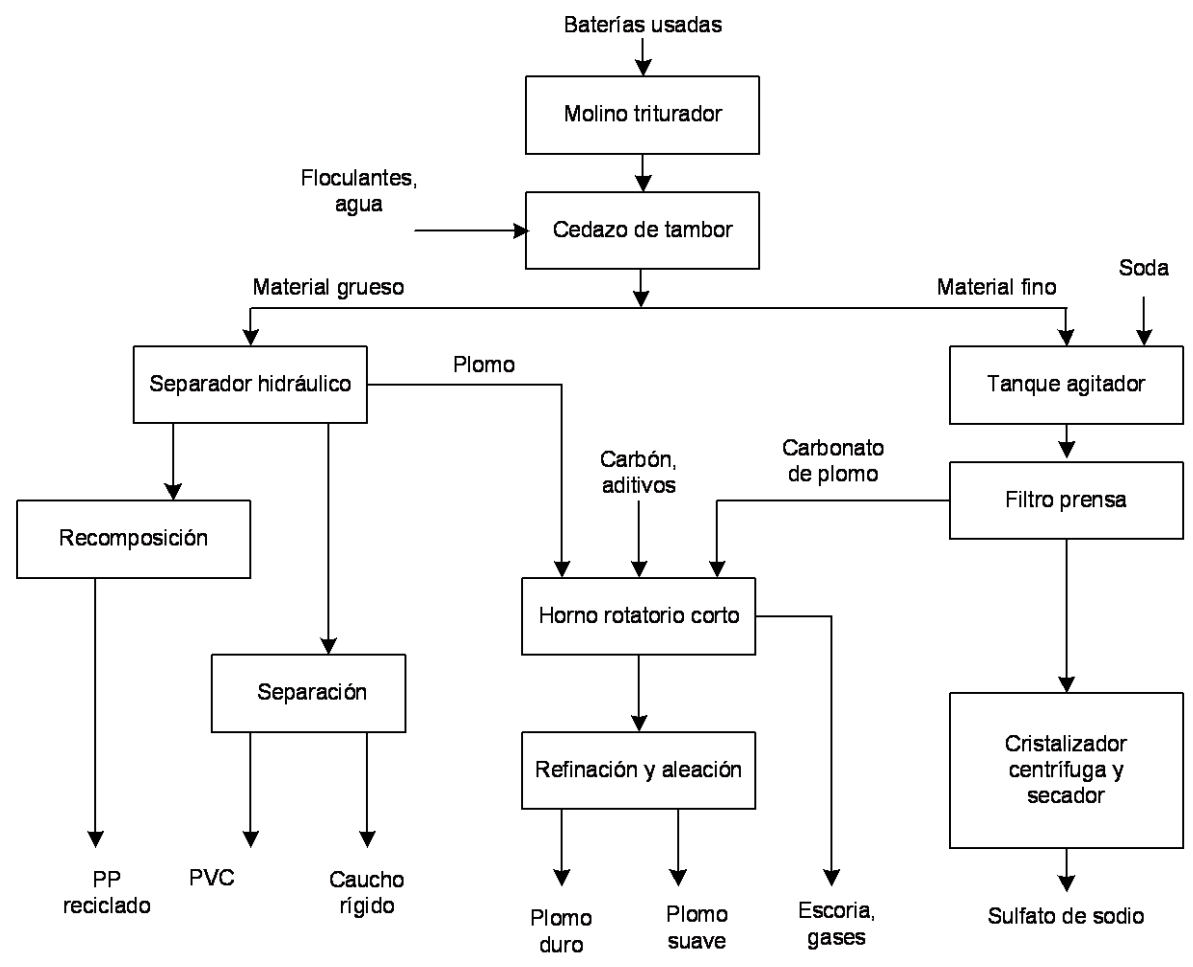

Fuente: Universidad Tecnológica de Aquisgrán, 1990.

\subsection{Zinc}

En la actualidad, el mayor consumo de zinc (más del 50\%) se destina a recubrimientos contra la corrosión de productos de acero (galvanizado). Por tal razón, la mayoría del zinc reciclado se origina en la fusión de chatarra de acero en el horno eléctrico (EAF) y los materiales de desecho del proceso de galvanizado (ceniza y costra). Otros usos del zinc incluyen aleaciones de cobre (20\%), de zinc (13\%) y compuestos químicos (10\%).

La alta temperatura del proceso de fusión en el EAF genera la volatilización del zinc y algo del hierro, y la producción de polvo fino de $\mathrm{EAF}$, que puede contener hasta $30 \%$ de zinc, dependiendo de la alimentación. Típicamente, la operación del EAF produce entre 10 y 15 kilogramos de polvos por tonelada de acero producido. Este polvo con- 
tiene $20 \%$ a $40 \%$ de $\mathrm{Fe}, 1$ a $4 \%$ de $\mathrm{Pb}, 0,5$ a $3 \%$ de $\mathrm{Cl}$, y 0,1 a $0,5 \%$ de F. El proceso predominante para fundir los materiales reciclados de alto contenido de zinc es el kiln rotatorio Waelz, donde el zinc es reducido, volatilizado y recuperado en forma de óxido impuro, con 50\% a $60 \%$ de $\mathrm{Zn}$. El residuo de hierro del kiln puede alimentarse con chatarra de hierro para producir nuevamente acero en el EAF.

El polvo de óxido de zinc puede procesarse en una planta de zinc primario por vía hidrometalúrgica convencional (disolución en ácido sulfúrico junto con los óxidos de zinc) o por fusión en el horno de cuba combinado de plomo-zinc (proceso Imperial Smelting). Este último tiene especial importancia porque permite procesar residuos y concentrados mixtos de plomo-zinc. El horno IS tiene la particularidad de utilizar un baño de plomo líquido recirculante para capturar por condensación el zinc volatilizado durante la fusión. El plomo y el zinc líquidos son luego separados en un baño por enfriamiento, según se observa en el esquema de la figura 9.

Fig. 9

\section{Esquema del proceso combinado de plomo-zinc en el horno Imperial Smelting.}

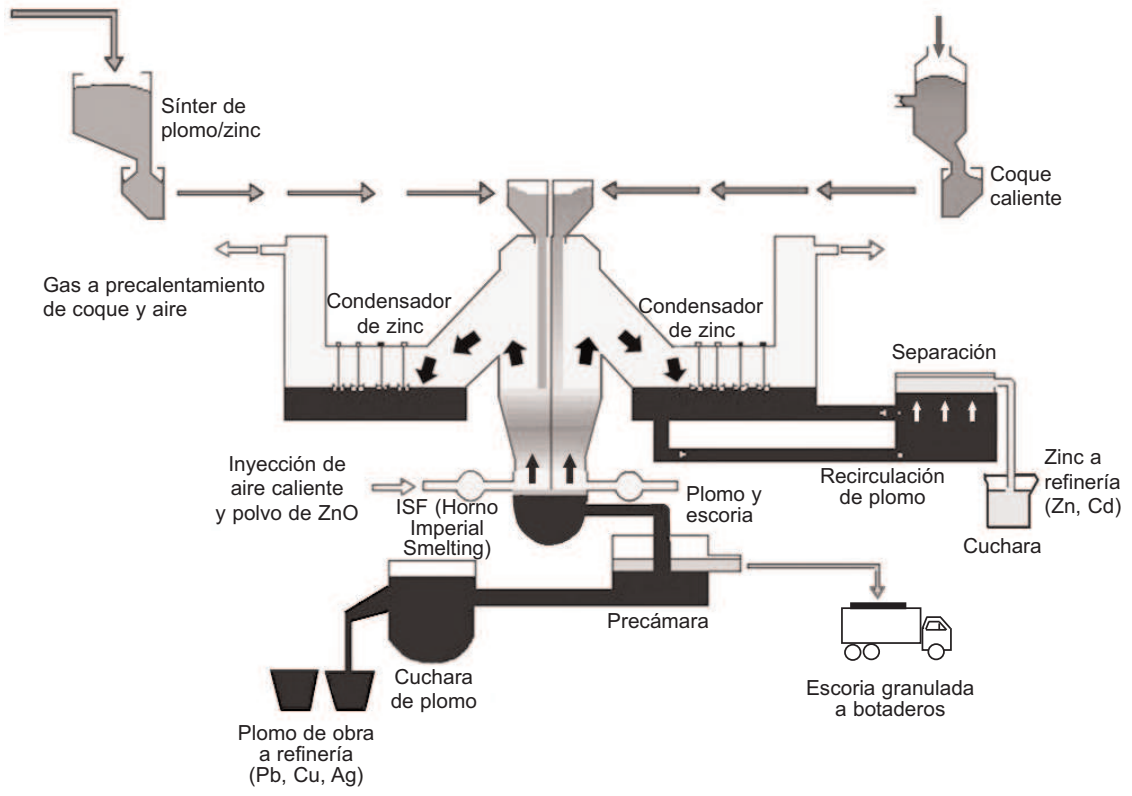

Fuente: Britannia Zinc-ISF. 


\section{CONCLUSIONES Y RECOMENDACIONES}

En los materiales metálicos deben distinguirse las fuentes de materias primas de origen primario (minerales, concentrados) y secundario (chatarra nueva y vieja, residuos). El reciclaje de los metales de la chatarra tiene una gran importancia en la economía y en la conservación de los recursos primarios, de la energía y del medio ambiente. Las tecnologías existentes permiten recuperar en alto grado los metales de las diversas fuentes de materias primas secundarias.

A la par con la tecnología adecuada, es importante la creación de una economía de reciclaje, ya que si bien los metales pueden reciclarse casi indefinidamente, sin que pierdan sus propiedades originales, es de gran importancia la clasificación y comercialización de chatarra en tipos y grados normados internacionalmente, evitando así la contaminación de las materias primas con chatarras de distinto nivel de aleación e impurezas.

\section{BIBLIOGRAFÍA}

Aluminum Beverage Cans. "The ABCs for environmental education". [en línea] <http://www.cancentral.com/canc/abc.htm>.

BCS Incorporated, U.S. Department of Energy. "Energy and environmental profile of the U.S. mining industry", 2002.

Environmental Society of Southern Methodist University. "Environmental Facts", [en línea]. <http://people.smu.edu/awma/environment/ facts.asp>.

Japan Automobile Manufacturer's Association (JAMA). "Research and development on automobile shredder residue compaction, solidification, dry distillation and gasification technology" [en línea] $<$ http://www.jama.or.jp>.

Krüger, J. Reciclaje de metales no ferrosos. Aquisgrán: Universidad de Tecnología de Aquisgrán, Instituto de Metalurgia Extractiva, 1990 .

Sasha Mackler, M. Managing municipal solid waste. Nueva York: Universidad de Columbia, Earth Engineering Center, 1999. 
Themelis, Nickolas J. "An overview of the global waste-to-energy industry”, Waste Management World, 2003-2004 Review Issue. Jullio-agosto, 2003. [en línea] $7<\mathrm{http}: / / \mathrm{www}$.iswa.org>.

Universidad Tecnológica de Aquisgrán, 1990.

U.S. Geological Survey Minerals Yearbook 2003. Recycling Metals, 2003.

Waste. "Metals. Aluminium and steel recycling". [En línea] $<$ http://www.wasteonline.org.uk>.

Wellmer, F. W. y M. Kosinowski. "Sustainable development and the use of nonrenewable resources". Geotimes. Diciembre del 2003. [en línea] <http://www.geotimes.org $>$.

Wernick, I y N. J. Themelis. "Recycling metals for the environment". Annual Reviews Energy and Environment, Vol. 23, 1998.

\section{Páginas web}

Britannia Zinc - ISF. [En línea] <http://www.bzl.co.uk>.

Bruch Metallwerke. [En línea] <http://www.bruch.de>. 